\title{
Prolocal: inclusão produtiva dos pequenos negócios como política de desenvolvimento municipal no Mato Grosso do Sul
}

\author{
Prolocal: productive inclusion of small businesses as a policy of city \\ development in Mato Grosso do Sul
}

\section{Prolocal: inclusión productiva de pequeños negocios como una politica municipal en Mato Grosso do Sul}

\author{
Prolocal: inclusion pructif de petit enterprise comment une policie municipal en Mato \\ Grosso do Sul
}

\author{
Cleonice Le-Bourlegat* \\ (clebourlegat@ucdb.br) \\ Sandra Amarilha** \\ (amarilha@gmail.com)
}

Recebido em 10/04/2013; revisado e aprovado em 11/08/2013; aceito em 17/09/2013

\begin{abstract}
Resumo: Com a missão de implementar políticas públicas para um ambiente favorável aos pequenos negócios, o SEBRAE Mato Grosso do Sul criou o projeto PROLOCAL. Este artigo analisa seus impactos na inclusão produtiva e dinamização econômica nos municípios de fronteira, instrumentalizado por quatro focos: formalização de empresas, agente de desenvolvimento, compras governamentais e desburocratização.

Palavras-chave: PROLOCAL, inclusão produtiva, desenvolvimento municipal.

Abstract: With the mission of implementing public policies for a small business friendly environment, SEBRAE Mato Grosso do Sul created PROLOCAL. This article analyses its impact in the productive inclusion and economic promotion in the frontier cities, using as an instrument four focuses: Companies Formalization, Development agent, governmental purchases and debureaucratisation.

Key words: PROLOCAL, Productive Inclusion, County Development.

Resumen: Con la misión de implementar políticas públicas para crear un ambiente favorable a los pequeños negocios, el SEBRAE Mato Grosso do Sul creó el proyecto PROLOCAL. Este artículo analiza sus impactos en la inclusión productiva y la dinamización económica en los municipios de frontera, instrumentalizado por cuatro focos: Formalización de empresas, agentes de desarrollo, adquisiciones gubernamentales y desburocratización. Palabras clave: PROLOCAL, Inclusión Productiva, Desarrollo municipal.

Resumé: Avec la misión de implimenter les politique public pour un enviroment favorable pour le petites entreprises, le SEBRAE Mato Grosso do Sul créé le projet PROLOCAL. Cet article examine son impact en le inclusión productif et avancement economìque des municípe de frontier, instrumentalizé pour quatre foyers : fomalizatión d'entreprise, agent de development, achet publics et desbureaucratization.

Mots-clés :Prolocal, Inclusión Productif, Development Municipal .
\end{abstract}

\section{Introdução}

A economia dinamizada por uma política de investimentos vindos de outros Estados na "Marcha para o Oeste" iniciada no governo Getúlio Vargas, ainda mantém na mentalidade coletiva, que a atração de grandes empresas vindas de outras regiões é a única solução para resolver os problemas de baixo dinamismo econômico e os baixos níveis de geração de emprego e renda (ESTERCI,1972, p. 19)

Estão entre os Municípios que apre- sentam maior dinamismo econômico dentro do Estado, de um modo geral, aqueles que se avizinham dos Estados da Região Sul e Sudeste como também, aqueles situados ao longo de corredores de transporte polarizados por Campo Grande e Dourados.

No entanto, mesmo sob os efeitos dos grandes investimentos a participação da produção sul-mato-grossense na formação da riqueza nacional não cresce relativamente mantendo-se na média de $1,20 \%$. As iniciativas para diversificação da matriz produtiva são recentes e os resultados ainda são gradativos.

\footnotetext{
* Universidade Católica Dom Bosco (UCDB), Campo Grande, MS, Brasil.

** Universidade Católica Dom Bosco (UCDB); SEBRAE/MS, Campo Grande, MS, Brasil.
} 
Essa dinamização que se interioriza de Leste para Oeste tem servido para ampliar a distinção da desigualdade já existente em relação aos Municípios mais interiores de Mato Grosso do Sul, especialmente aqueles situados na região da Faixa de Fronteira, onde prevalecem os mais baixos indicadores de desenvolvimento humano. Além disso, os pequenos municípios com menos de $50 \mathrm{mil}$ habitantes, abrangem 73 dos 79 existentes no Estado, que apresentam forte dependência dos programas sociais.

Os municípios fronteiriços têm sido alvo de preocupação de políticas federais de inclusão produtiva por parte do Ministério da Integração Nacional (Programa de Desenvolvimento da Faixa de Fronteira (PDFF)), do Ministério do Desenvolvimento Agrário (territórios da cidadania) e do Banco do Brasil (estratégias de Desenvolvimento Regional Sustentável).

A problemática deste artigo diz respeito à forma como os Municípios mais vulneráveis da Fronteira Agrícola de Mato Grosso do Sul estariam respondendo ao processo de implementação do PROLOCAL e que natureza de impactos já poderia ser identificada em relação à inclusão produtiva desses Municípios.

Parte-se da hipótese que o desenvolvimento local, por suas características, é um processo que possibilita o fortalecimento e autonomização dessas áreas de forma integrada por meio de redes de articulação, aprendizagem e governança. Mas como esse processo é pautado em mudanças de valores e crenças, acompanhado de um protagonismo e identificação de potencialidades, ele pode exigir, no caso de sociedades mais vulneráveis como o território alvo da pesquisa, políticas mais efetivas e customizadas na sua implantação.

Existem dois objetivos específicos nesse processo de desenvolvimento territorial: (1) Verificar em que estágio se encontra a municipalização da Lei Geral como instrumento de apoio ao desenvolvimento de competências locais; (2) Identificar formas encontradas de inclusão produtiva de micro e pequenas empresas locais, observando-se com nível maior de detalhamento os benefícios do uso do poder de compra dos órgãos públicos nesse sentido.

\section{SEBRAE como agente de política pública de desenvolvimento municipal}

Nesse novo contexto de políticas de inclusão produtiva, o Serviço Brasileiro de Apoio às
Micro e Pequenas Empresas (Sebrae) assume o papel de agente de desenvolvimento, procurando atuar como articulador de parceiros públicos e privados em projetos de fortalecimento de micro e pequenas empresas (MPEs) em seus territórios de manifestação. Essas iniciativas ocorrem num processo de desenvolvimento territorial, no qual os atores econômicos locais e o tecido institucional de apoio são desafiados a se solidarizar em iniciativas coletivas de aprendizagem e de governança, visando construir competências territoriais de inclusão produtiva.

Tendo em vista o contexto de políticas federais previstas nos Planos "Brasil Maior" e "Brasil sem Miséria", a regulamentação da Lei Geral para Micro e Pequenas Empresas nos Municípios e a incumbência de agente mobilizador do desenvolvimento local com base no fortalecimento das MPEs, o Sebrae de Mato Grosso do Sul lançou-se ao desafio da implementação da Lei Geral da micro empresa - Lei complementar 123/ 2006 em todo Estado e ao processo paralelo de inclusão produtiva nos territórios municipais mais vulneráveis, por meio do desenvolvimento local.

Desde 2011, o projeto denominado PROLOCAL foi executado em 21 Municípios do Estado com menos de 50 mil habitantes no esforço de municipalização da lei. Até maio de 2012, dos 78 municípios que compõe o Estado, 62 já haviam cumprido a meta de regulamentação, ou seja, 79\% dos municípios. No entanto, o PROLOCAL mantém o desafio de intensificar os dispositivos de aplicação efetiva da lei em 21 Municípios, em sua primeira fase que vai de 2011 a 2013, devendo ser expandido para mais municípios assim que lograr êxito.

Conforme Le-Bourlegat, 2011 obter resultados transformadores em realidades complexas requer articulação de atores que possam alavancar o processo, e, adesão do público alvo. Dessa forma o SEBRAE compartilhou com as entidades de seu conselho deliberativo a autoria do PROLOCAL e lançou em 15 de fevereiro de 2011 o edital para seleção dos municípios que seriam assistidos com uma série de ações intensificadas de qualificação e apoio empresarial. As prefeituras para receberem o benefício de serem assistidas pelo Sistema $S$ se comprometeram a regulamentar a Lei Geral e cumpri-la, iniciando pela nomeação de um Agente de Desenvolvimento e 
disponibilizando o mesmo para capacitação, a cargo do SEBRAE, como primeiro passo.

\section{Micro e pequena empresa e a lei geral}

O Estatuto das microempresas e empresas de pequeno porte, instituído pela Lei n. 9841 de 5 de outubro de 1999, apresenta um conjunto de normas jurídicas para tratamento diferenciado em questões: documentais, administrativas, trabalhistas, previdenciárias e creditícias e altera para faturamento, o critério de enquadramento outrora baseado no número de funcionários, referendado posteriormente pela Lei Complementar 123 de 2006.

\begin{tabular}{|l|l|}
\hline Porte & Faturamento \\
\hline Microempresa & $\begin{array}{l}\text { Receita bruta igual ou inferior a R\$ 360.000,00 (trezentos e sessenta mil } \\
\text { reais) }\end{array}$ \\
\hline $\begin{array}{l}\text { Empresa de pequeno } \\
\text { porte }\end{array}$ & $\begin{array}{l}\text { Receita bruta superior a } \mathbf{R} \mathbf{3 6 0 . 0 0 0 , 0 0} \text { (trezentos e sessenta mil reais) e } \\
\text { igual ou inferior a R\$ 3.600.000,00 (três milhões e seiscentos mil reais). }\end{array}$ \\
\hline
\end{tabular}

Quadro 1 - Critérios de definição do porte das empresas no Brasil

Fonte: Lei 9841/1999 e Lei Complementar 123/2006

A micro e a pequena empresa, de acordo com Koteski (2004) representa um dos principais pilares de sustentação da economia brasileira, tanto por sua capacidade geradora de empregos, como pelo significativo número de estabelecimentos disseminados em vários pontos do país. Os pequenos negócios apresentam estruturas flexíveis com potencialidade para responder melhor e mais rapidamente às crises econômicas.

A globalização e a abertura econômica, segundo Amaral (2002), tem exigido um enorme desafio no campo da competitividade empresarial, gerando deslocamento dos investimentos na busca de mão-de-obra barata e concorrência entre os territórios. Nesse processo, ocorreu desintegração vertical das grandes empresas e integração horizontal das pequenas e médias empresas, valorizando o território e seus atores. Os agrupamentos em redes e organizações coletivas tem sido motivo de grandes renovações para as MPEs, de novas possibilidades de emprego e renda e de fortalecimento do tecido produtivo, possibilitando processos de desenvolvimento endógeno.

A Lei Geral (123/2006) foi um grande marco no que diz respeito à efetivação do disposto no artigo 179 da Constituição Federal de 1988, que preceitua que "a União, os Estados, o Distrito Federal e os Municípios dispensarão às microempresas e às empresas de pequeno porte, assim definidas em lei, tratamento jurídico diferenciado, visando a incentiválas pela simplificação de suas obrigações administrativas, tributárias, previdenciárias e creditícias, ou pela eliminação ou redução destas por meio de lei".

\section{O que é implementar a lei geral?}

A Lei Geral para Micro e Pequenas Empresas, Lei Complementar n. 123 sancionada em 2006 transformou-se em instrumento facilitador de inclusão produtiva dos pequenos negócios, na medida em que contribui para regularizar e ampliar suas vantagens competitivas no território vivido, ou melhor, onde estão sediadas.

A legislação tem uma função modernizadora ao potencializar, entre outros, os paradigmas de: (1) Estabelecimento da confiança prévia no empreendedor; (2) Resgate do papel orientador da fiscalização; (3) Aprofundamento da capacidade contributiva em um sistema tributário mais justo; (4) Uso da política pública de compras do Estado para impulsionar a pequena economia que estava alijada de participar das licitações; (5)A promoção do desenvolvimento local. (METZKER, 2009).

A regulamentação da LEI GERAL desde 2006 ocorre de forma lenta, exigindo muito esforço do SEBRAE juntos aos gestores municipais. Teve início o processo de regulamentação junto aos Municípios em Mato Grosso 
do Sul em 2011. Em 20 de maio de 2012 - 63 municípios no MS.

Nassif, 2007 indica alguns passos para a efetivação de uma estratégia de âmbito nacional, como a atuação do Sebrae no esforço de implementação da Lei Geral. Primeiramente, ele afirma que a questão-chave é definir um objetivo estratégico. Para o Sebrae, o objetivo principal é a concepção de um modelo de desenvolvimento que tenha como base os dispostos da Lei Complementar 123/2006.

Ainda há uma série de artigos da Lei Geral que necessita de regulamentação nos municípios. No intuito de acelerar esse processo, o Sebrae, sensibiliza para a regulamentação e implementação da Lei Geral para Micro e Pequenas Empresas nos municípios brasileiros.

Contudo, a aprovação do marco legal foi apenas um ponto de partida. Para que os dispositivos se efetivem, é preciso um esforço para regulamentação da legislação no município e, posteriormente, para a implantação de uma estratégia de implementação. Caso contrário, o avanço que a Lei Geral traz fica tolhido.

Regulamentação é diferente de implantação, ou também chamada de municipalização, já que nesse caso, o desafio é implantar a lei como uma medida de apoio ao processo de desenvolvimento do município por meio do fortalecimento da MPE. No presente estudo foi analisada a efetividade e eficácia desse processo de implementação instrumentalizado no PROLOCAL.

Segundo Nassif, para atingir o objetivo proposto, é preciso definir uma lista restrita de prioridades. Nesse sentido, a Unidade de Desenvolvimento Territorial do Sebrae (UDT) formulou um sistema de monitoramento da implementação da Lei Geral, no qual inicialmente foram eleitos quatro, entre os vários dispositivos da lei geral, para serem trabalhados prioritariamente: empreendedor individual; desburocratização; uso do poder de compra; e agente de desenvolvimento local, que denominam-se como eixos prioritários no PROLOCAL.

Na lógica dos eixos prioritários, ao nomear um agente local de desenvolvimento, capacitá-lo, dar-lhe autonomia para agir, derrubar as barreiras burocráticas para investimento empresarial e estimular a formalização, as condições básicas para a competitividade local instalam-se, e são estimuladas por perspectivas de um novo mercado: o potencial de compra das prefeituras, que pode exercer papel ativo de agente econômico ao irrigar a economia comprando de fornecedores locais. É a força de uma oportunidade de mercado impulsionando para um ciclo virtuoso da economia, aqui se estabelece a lógica do PROLOCAL.

A municipalização da Lei Geral convergente ao processo de desenvolvimento territorial passa por ganhos gradativos que compreendem (1) Mobilização da sociedade civil, (2)Sensibilização de agentes públicos, (3) Ampliação das competências locais por processos coletivos de aprendizagem, (4) Adequação do ambiente legal para que o mercado opere a favor do desenvolvimento e (5) Dinamização da economia.

\section{O PROLOCAL como instrumento de política pública para desenvolvimento}

Ao buscar inclusão produtiva num cenário
de crescimento econômico, orienta-se para
uma visão compartilhada de futuro na qual
a micro e a pequena empresa exerça papel
de sustentação, que o caminho seja trilhado
com planejamento participativo protago-
nizado por atores locais. Esses elementos
estão presentes no PROLOCAL, projeto de
apoio ao desenvolvimento econômico dos
municípios fundamentado na Lei Geral, co-
ordenado pelo SEBRAE, e objeto de analise
no presente estudo.
Com base em Boisier (1998) há dois requisitos básicos para que se efetue intervenções territoriais inteligentes com possibilidade de êxito: a construção de um novo conhecimento e a construção do poder político local/regional. Tudo isso ocorre, ou não, com mais ou menos intensidade, dependendo muito da cultura cívica, capital social ou da densidade e qualidade institucional acumulada no território/região. Dadas estas condições e atendidos os requisitos, torna-se possível atingir um objetivo altamente almejado pelos atores, agentes participativos que atuam no processo de desenvolvimento local-regional, que é o de superar a dependente condição de território-palco, para a de território-ator. E que desse processo virtuoso, pelo exercício de um processo permanente de concertação 
social, resulte a constituição de um novo pacto socioterritorial (BOISIER, 1998, p. 53-69).

Dessa forma, é possível atingir outro passo apontado por Nassif: a transformação dos princípios em agenda, através de abordagens segmentadas, que é exatamente o que Sebrae faz ao criar medidas que aumentem o envolvimento do entes públicos com os mecanismos da Lei Geral. "Cada região tem que traduzir para ela a estratégia que o país adotou para si" (NASSIF, 2007). Essa categoria conceitual torna-se fundamental na análise das formas e condições de participação dos atores locais na implementação do PROLOCAL, vislumbrados na possibilidade de mobilização e inclusão produtiva das micro e pequenas empresas, transformarem seu Município num território-ator.

São fases do PROLOCAL:

\begin{tabular}{|l|}
\hline 1. Construção do conhecimento e pacto territorial \\
\hline 1.1. Lançamento do edital de seleção dos municípios \\
\hline 1.2. Diagnostico das empresas - Negócio a Negócio \\
\hline 1.3. Evento de Lançamento municipal do projeto \\
\hline 1.4. Entrevistas estruturadas com lideranças \\
\hline 1.5. Empresário oculto - simulador de barreiras burocráticas para formalização de empresas \\
\hline 1.6. Oficina Analise S.W.O.T : ambiente empresarial \\
\hline 1.7. Elaboração do Plano de Ação compartilhado \\
\hline 1.8. Publicação do plano de ação municipal \\
\hline 1.9. Publicação do conhecimento qualificado \\
\hline 1.10. Publicação do diagnostico de desburocratização \\
\hline 1.11. Publicação do mapa de oportunidades p/ novos negócios \\
\hline 2. Estratégias de políticas públicas - implementação da lei geral \\
\hline 2.1. Formação da rede de agentes de Desenvolvimento \\
\hline 2.2. Revisão das leis e práticas relacionadas as compras públicas e incentivos fiscais \\
\hline 2.3. Capacitação dos agentes de desenvolvimento para tratamento diferenciado a MPE \\
\hline 2.4. Assessoria aos gestores públicos e implantação da sala do empreendedor; \\
\hline 3. Estratégias para Competitividade Sistêmica \\
\hline 3.1. Ações de estímulo ao empreendedorismo local \\
\hline 3.2. Ações de capacitação e consultoria empresarial conforme plano de ação local; \\
\hline 3.3. Apoio técnico na formulação de projetos para desenvolvimento de sistemas produtivos \\
\hline locais \\
\hline 3.4. Uso do poder de compras das prefeituras - inclusão produtiva dos pequenos negócios \\
\hline Q.5. Qualificação empresarial de potenciais fornecedores das prefeituras e escolas estaduais \\
\hline
\end{tabular}

Quadro 2 - Etapas do PROLOCAL. Elaborado pela autora, 2011.

O PROLOCAL apresenta-se como instrumento institucional para criar a ambiência legal favorável à inclusão produtiva dos pequenos negócios e a aprendizagem coletiva nos territórios, principalmente naqueles onde não há grandes empresas instaladas.

A oportunidade dada a todos os municípios com menos de 50 mil habitantes, abrangia 73 municípios do Estado, em 2011, ficando de fora apenas: Campo Grande, Ponta Porã, Corumbá, Dourados e Três Lagoas. Mesmo assim apenas 35 candidataram-se e conforme os critérios estabelecidos, e 21 foram selecionados.
Desses 21(vinte e um) municípios selecionados, situam-se na faixa de fronteira com até 150 (cento e cinquenta) quilômetros da linha fronteiriça, 9 (nove) deles, que são: Maracaju, Sidrolândia, Nioaque, Bodoquena, Itaquiraí, Caarapó, Porto Murtinho, Aral Moreira e Mundo Novo. O foco da análise foi limitado aos três municípios situados exatamente na linha de fronteira com o Paraguai, e, portanto, objeto de aprofundamento deste estudo, em função da diferenciação das transações comerciais e evasão de renda pelo consumo transfronteiriço. 


\section{Os impactos do PROLOCAL}

A implementação da lei geral requer mudanças nos procedimentos e praticas governamentais na consecução das metas e promove possibilidades de alteração no formato institucional do processo decisório, articulação público-privada na formulação de políticas, abertura maior ou menor para a participação dos setores interessados (BANCO MUNDIAL, 1992, apud DINIZ, 1995, p.400).

Novos e importantes atores somaram ao esforço de implementação. Em março de 2013, o TCE- tribunal de contas do estado, assinou com SEBRAE, Assomasul e Governo do Estado o compromisso de fazer cumprir a lei, sendo que ainda em 2013 irá desempenhar um papel educativo para a partir de 2014 aplicar as sanções àqueles gestores municipais que não cumprirem a lei promovendo tratamento diferenciado aos pequenos negócios de seu município.

Para efeito deste estudo aplicou-se nos 21 municípios uma pesquisa de monitoramento, baseado nos quatro eixos principais da implementação da Lei Geral, que são: (a) agente de desenvolvimento; (b) empreendedor individual; (c) desburocratização e (d) uso do poder de compras.

Para cada eixo prioritário da lei geral, definiu-se um objetivo estratégico, e sob essa matriz, o indicador de implementação da lei geral.

\begin{tabular}{|c|c|c|}
\hline EIXO PRIORITÁRIO & FOCO DA AVALIAÇÃO & PONTUAÇÃO \\
\hline $\begin{array}{l}\text { Agente de } \\
\text { desenvolvimento }\end{array}$ & Designação e Plano de trabalho efetivo & 1,4 \\
\hline \multirow{3}{*}{$\begin{array}{l}\text { Empreendedor } \\
\text { individual }\end{array}$} & Inserção do EI na base de dados do município & \multirow{3}{*}{2} \\
\hline & Dispensa do habite-se do imóvel que o EI e registrado & \\
\hline & $\begin{array}{l}\text { Manutenção do IPTU residencial para o EI que exerce } \\
\text { atividade em sua residência }\end{array}$ & \\
\hline \multirow{3}{*}{ Desburocratização } & Tempo médio de abertura das empresas & \multirow{3}{*}{2,3} \\
\hline & Especificação das atividades e respectivos graus de riscos & \\
\hline & Concessão de alvará de funcionamento provisório & \\
\hline \multirow{4}{*}{$\begin{array}{l}\text { Uso do poder de } \\
\text { compra }\end{array}$} & Participação dos pequenos negócios nas compras municipais & \multirow{4}{*}{4,3} \\
\hline & $\begin{array}{l}\text { Editais exclusivos para participação dos pequenos negócios } \\
\text { até } \mathrm{R} \$ 80.000,00\end{array}$ & \\
\hline & Subcontratação de até 30\% do valor licitado & \\
\hline & Cota de até $25 \%$ de bens de natureza divisível & \\
\hline Total & & 10 \\
\hline
\end{tabular}

Quadro 3 - Matriz de implementação da lei geral. SEBRAE. Diretrizes estratégicas para implementação da lei geral nos municípios. Dezembro, 2011.

Conforme mencionado uma série de variáveis referentes aos dispositivos que as prefeituras devem adotar, mais precisamente 58 foram avaliadas por meio do Sistema de Monitoramento da Lei Geral. A partir daí, é possível observar se a Lei Geral da Micro e Pequena Empresa é praticada pelos gestores públicos municipais.

O foco de análise dos quatro grandes eixos (uso do poder de compra do município; desburocratização da abertura, funcionamento e fechamento de empresas; empreendedor individual e agente de desenvolvimento) se dá a partir do acompanhamento e monitora- mento da ação pública sob quatro aspectos: Regulamentação; Operacionalização; Esforço; Resultados. Ou seja, são pontuadas além da atuação das prefeituras em prol da regulamentação a Lei Geral a sua aplicabilidade (operacionalização), bem como os esforços dos gestores municipais em ações que não estão obrigatoriamente previstas na legislação, mas que certamente são fundamentais para a observância da mesma.

A lógica do Indicador parte, do pressuposto que os municípios devem por em prática pontos específicos da Lei Geral, a partir de uma aplicação mínima de alguns 
dispositivos, o município será qualificado como tendo implementado o eixo analisado. O sistema de monitoramento da implementação da Lei Geral permite mensurar localmente os impactos da estratégia nacional, no caso o desenvolvimento calcado no Estatuto da
Micro e Pequena Empresa

Aplicando-se o instrumento de pesquisa para avaliação do município - Implementação da Lei Complementar 123/2006, conforme método de pontuação por eixo, surge o quadro abaixo:

\begin{tabular}{|c|c|c|c|c|c|c|c|c|c|c|c|c|c|c|c|c|c|c|c|c|}
\hline 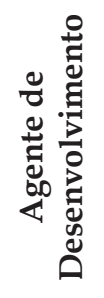 & 으 & 응 & $\begin{array}{l}\infty \\
\infty \\
\infty\end{array}$ & 으 & $\mid \begin{array}{l}2 \\
\infty \\
\infty\end{array}$ & $\mid \begin{array}{l}\infty \\
\infty\end{array}$ & 으 & 익 & 의 & 이 & 이 & 의 & 이 & ชુ: & 2 & $\theta=$ & 윽 & 이 & 0 & 의 \\
\hline 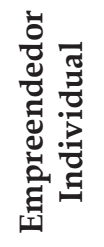 & 둔 & $\begin{array}{l}3 \\
\infty \\
\infty\end{array}$ & $\hat{\mathrm{i}}$ & 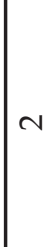 & $\Rightarrow$ & $\begin{array}{l}n \\
0 \\
0\end{array}$ & $\begin{array}{l}\curvearrowright \\
\phi^{\prime}\end{array}$ & $\cong$ & $\widehat{ल}$ & $\begin{array}{l}2 \\
m^{2}\end{array}$ & $\stackrel{1}{1}$ & भे & 誌 & $\overrightarrow{\mathrm{F}}$ & $\begin{array}{lll}5 & \\
& \end{array}$ & $\Rightarrow$ & $\mid \begin{array}{c}N \\
15 \\
15\end{array}$ & ถે & $\stackrel{\infty}{+}$ & $\begin{array}{l}+ \\
\infty \\
\infty\end{array}$ \\
\hline 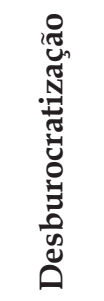 & ما & $\stackrel{+}{\Lambda}$ & $\underset{+}{\sim}$ & $\stackrel{\infty}{+}$ & $\stackrel{2}{2}$ & $\left|\begin{array}{l}10 \\
10\end{array}\right|$ & $\left|\begin{array}{c}0 \\
15\end{array}\right|$ & 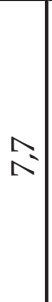 & $\stackrel{2}{\stackrel{2}{+}}$ & $\begin{array}{l}0 \\
n^{2}\end{array}$ & کิ & $\infty$ & તુ. & \begin{tabular}{c|c}
$\infty$ & $\tilde{c}$ \\
\end{tabular} & \begin{tabular}{c|c}
5 \\
3
\end{tabular} & $\begin{array}{ll}0 \\
n^{2} \\
n^{2}\end{array}$ & 弄 & $\underset{+}{+1}$ & $\overrightarrow{10}$ & - \\
\hline 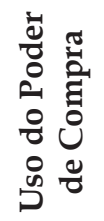 & 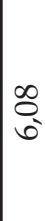 & $\begin{array}{l}18 \\
0 \\
11\end{array}$ & 今 & $\begin{array}{l}0 \\
0 \\
15\end{array}$ & $\mid \begin{array}{l}\infty \\
2 \\
n^{2}\end{array}$ & $\begin{array}{l}0 \\
\cdots \\
\sigma^{2}\end{array}$ & 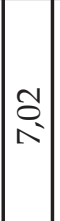 & $\begin{array}{l}\stackrel{0}{\infty} \\
\stackrel{0}{*}\end{array}$ & 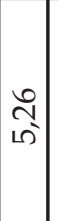 & 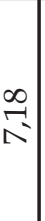 & $\mid$\begin{tabular}{|c|}
$\overrightarrow{2}$ \\
$\infty$
\end{tabular} & $\stackrel{\infty}{\stackrel{\infty}{\wedge}}$ & 赏 & 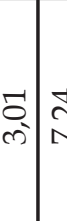 & ث̦ & \begin{tabular}{l|l}
0 \\
0 \\
0 \\
0
\end{tabular} & $\left|\begin{array}{l}0 \\
0 \\
\infty\end{array}\right|$ & \begin{tabular}{l}
+1 \\
\multirow{2}{*}{} \\
0
\end{tabular} & a. & $\begin{array}{l}\text { సे } \\
\infty\end{array}$ \\
\hline 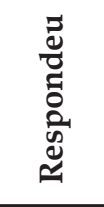 & us & os & $\omega$ & $\omega$ & $\infty$ & $\infty$ & $\infty$ & $\infty$ & $\infty$ & $\infty$ & $\infty$ & $\infty$ & $\infty$ & o 0 & 0 & $s$ & $\infty$ & $\infty$ & $\infty$ & $\infty$ \\
\hline 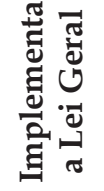 & os & os & $\mid \begin{array}{l}0 \\
\text { 至 } \\
\end{array}$ & $\mid \begin{array}{l}0 \\
i \\
z \\
z\end{array}$ & $\infty$ & $\infty$ & $\infty$ & $\infty$ & $\mid \begin{array}{c}0 \\
i \\
i \\
Z\end{array}$ & $\infty$ & $\infty$ & $\infty$ & $\infty$ & o & 0 & $s \infty$ & $\infty$ & $\begin{array}{c}0 \\
\text { Z } \\
\text { Z }\end{array}$ & $\infty$ & $\infty$ \\
\hline 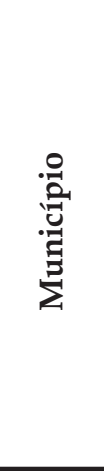 & 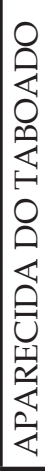 & 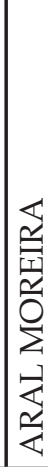 & 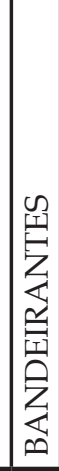 & 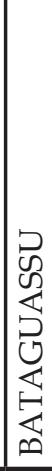 & 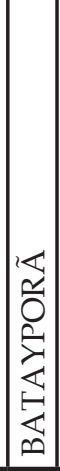 & 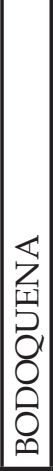 & 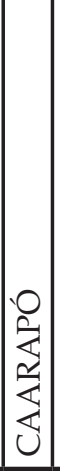 & 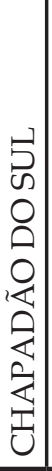 & 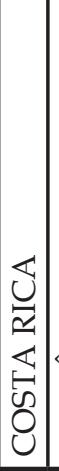 & 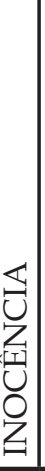 & 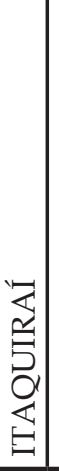 & 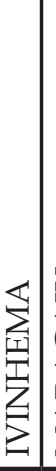 & 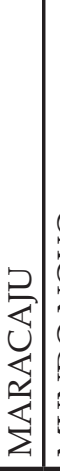 & 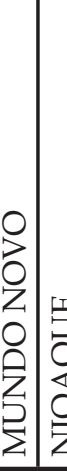 & 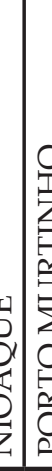 & 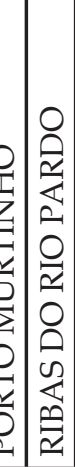 & \begin{tabular}{|c|} 
\\
\\
0 \\
$\frac{1}{0}$ \\
0 \\
$\frac{1}{Z}$ \\
0 \\
$\frac{1}{\simeq}$ \\
\end{tabular} & 芯 & 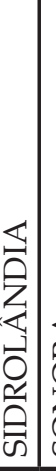 & 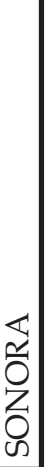 \\
\hline
\end{tabular}


Do grupo prioritário dos 21 municípios alvo do PROLOCAL, não foram bem sucedidos na implementação da lei até o mês de agosto de 2013 apenas os municípios de Bandeirantes, Bataguassu, Costa Rica, Mundo Novo e Selvíria.

Da linha de fronteira Aral Moreira e Porto Murtinho implementaram a contento, somente Mundo Novo não apresentou sucesso. O capítulo V da lei, "Do acesso aos mercados", abre a possibilidade para os municípios adequarem seus processos licitatórios ao desenvolvimento local, por meio da priorização dos pequenos negócios. (a) licitações de até R \$ $80.000,00$ exclusivas para micro e pequenas empresas; (b) subcontratação de até 30\% do total licitado para micro e pequenas empresas e (c) cotas de até $25 \%$ em aquisições de bens e serviços de natureza divisível.

Uso do poder de compras por parte do poder público abre uma oportunidade de inclusão de micro e pequenas empresas nesse mercado potencial, e evita que haja drenagem dos recursos locais para grandes empresas e multinacionais.

As oportunidades de circulação local da renda aplicam-se desde a aquisição da merenda escolar localmente dos pequenos produtores, a contratação de serviços de pequenos reparos, manutenção de veículos, aquisição de materiais de consumo, construção, abrindo um significativo mercado para pequenos negócios. Estas empresas, com o aumento das vendas e as perspectivas de planejamento do fornecimento irão gerar empregos locais e contribuir para arrecadação de impostos na economia formal, que se reverterá em benefícios à cidade, a saúde, educação, enfim gerando o ciclo virtuoso da economia.

Quando há ativação da economia local por meio dos recursos já disponíveis, pode corrigir efeitos de drenagem de recursos, substituindo por efeitos de irrigação da economia, que constituem também importantes fatores dinamizadores.

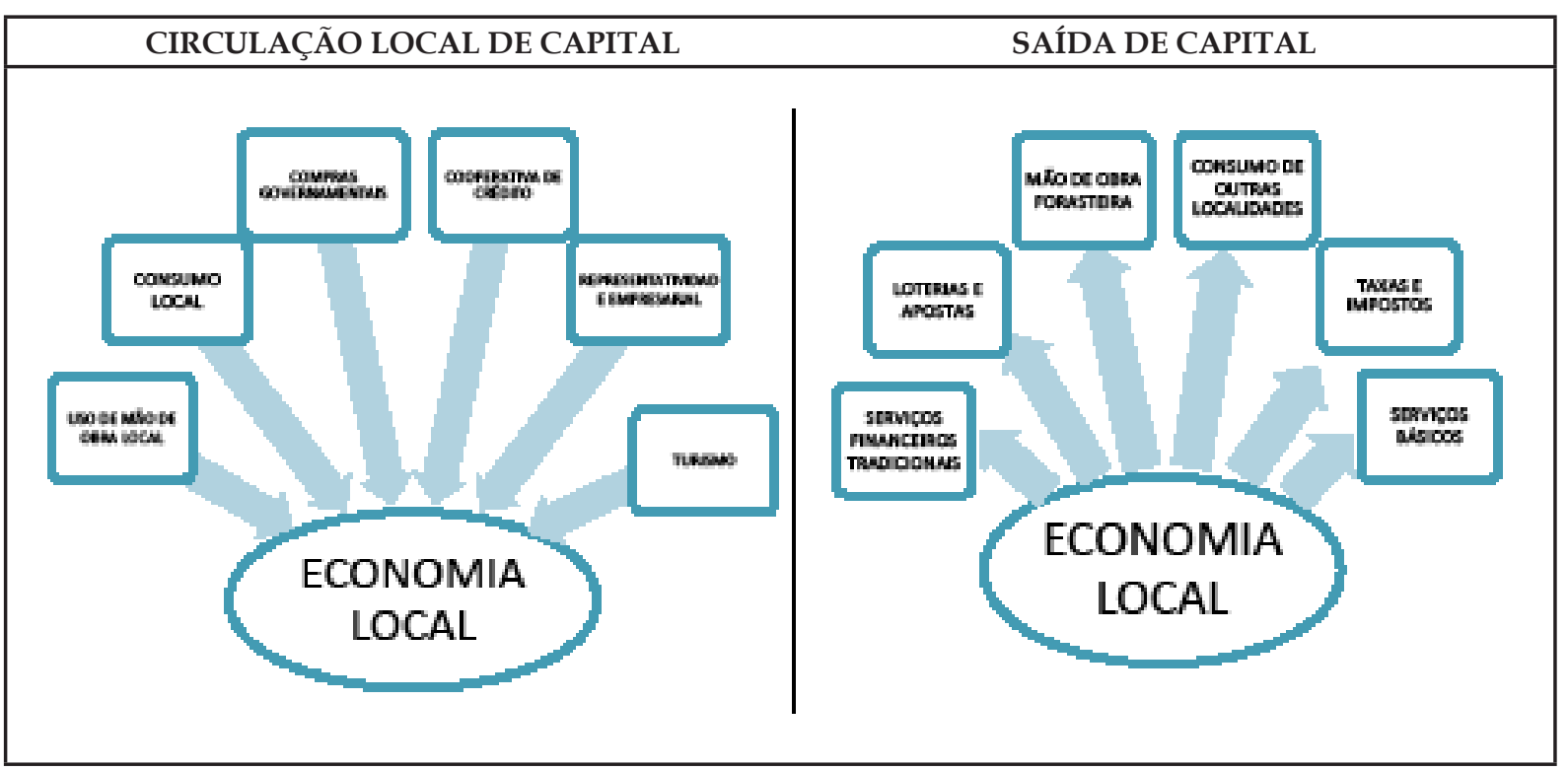

Quadro 5 - Irrigação e drenagem de recursos na economia municipal Elaborado pela autora, 2013.

A compra local permite ao dinheiro circular dentro do território, abastecendo outras empresas e movimentando o consumo. Ao trocar de mãos o dinheiro atende às necessidades de consumo das pessoas pelas quais passa, motivando o reabastecimento das mercadorias consumidas e permitindo às empresas aumentar sua escala de comer- cialização. Economicamente falando, a cada nova compra com o mesmo capital, maior o PIB registrado na região. Ao utilizar mão de obra local as necessidades de consumo do empregado serão satisfeitas na própria cidade, com consumo local.

Fator de relevância no aproveitamento dos recursos disponíveis em determinado 
território, as compras governamentais desempenham relevante papel. Em diversas cidades, principalmente naquelas menores, a prefeitura é o principal comprador de produtos e serviços, em torno dela se movimenta a economia local. Entretanto, muitos recursos saem da cidade no momento em que a prefeitura adquire produtos e serviços de outras localidades, como cidades e regiões próximas. Ao invés de promover o desenvolvimento de suas próprias empresas a prefeitura torna-se promotora do desenvolvimento vizinho.

O capítulo V, da Lei Complementar 123, prevê tratamento diferenciado para as Micro e Pequenas Empresas em compras do governo. As prefeituras, ao implementar a Lei Geral e utilizar seus dispositivos na promoção das empresas locais colaboram com o crescimento econômico injetando recursos na localidade, recursos estes que serão utilizados no pagamento de mão de obra local e na compra de outros produtos e serviços, atuando assim como gatilho de ativação da economia local.

Quando se elenca no PROLOCAL o fomento as compras locais, busca-se a irrigação da economia através da criação de competências nas pequenas empresas locais e na agricultura familiar viabilizando negócios com a Prefeitura, Escolas Públicas e demais instituições públicas. A Lei da Merenda também atua neste sentido, direcionando $30 \%$ dos recursos para aquisição de merenda escolar para os produtos da agricultura familiar. Este simples movimento é capaz de evitar que parte das riquezas produzidas localmente seja drenada do território. Iniciando no elo primário da economia, presente em todos os municípios sul-mato-grossenses independente de porte, recursos federais disponíveis nos Programas de Aquisição de Alimentos/PAA e Programa Nacional de Alimentação Escolar/PNAE por si já representam elementos dinamizadores a inclusão produtiva.

Os ganhos obtidos pela ativação da economia local escapam ao entendimento de um observador comum. As externalidades econômicas geradas pelas alternativas apresentadas potencializam o território e empoderam seus habitantes de forma além daquela que poderia ser inicialmente prevista.

A dinamização de cada atividade articula as demais gerando ganhos (chamados de externalidades) que promovem o desenvolvimento do conjunto das atividades econômicas presentes no território. Seguindo as leis de mercado, ao ativar a economia local aumentase a quantidade de moeda no território e a velocidade com que ela circula.

\section{Considerações finais}

Aprendendo com Paulo Freire,1979, não bastou tomar consciência do estágio que se encontravam os 21 territórios municipais alvo do projeto, foi necessário organizar todo um método, um arcabouço de ações para produção de mudanças da realidade local até o processo de transformação do conhecimento conforme preconizado por Nonaka e Takeushi $(1997$, p. 67) para a articulação dos modelos mentais de atores do desenvolvimento, os pactos e a produção de conhecimento ainda na $1^{\text {a }}$ fase do PROLOCAL.

Reportando ao problema original da pesquisa, questionando a forma como os Municípios mais vulneráveis da Fronteira de Mato Grosso do Sul estariam respondendo ao processo de implementação do PROLOCAL e que natureza de impactos já poderia ser identificada em relação à inclusão produtiva desses Municípios, conclui-se que a localização em fronteira com Paraguai, não foi fator impeditivo para a evolução no estágio de implementação da lei geral, tanto que nas oficinas com as lideranças dessas localidades sua condição geográfica não foi percebida como ponto fraco ou ameaça ao desenvolvimento.

$\mathrm{O}$ fato de Mundo Novo não ter implementado a Lei Geral, e apresentar desempenho inferior no diagnostico se comparado aos seus pares de condição fronteiriça: Aral Moreira, Porto Murtinho pode ser explicado pelo baixo grau de adesão ao projeto, ou seja, enquanto os agentes de desenvolvimento destes dois últimos cumpriram a risca todo o plano de capacitações, Mundo Novo não nomeou agente formalmente. Se comparado ao quadro total dos 21 municípios participantes do projeto encontram-se ainda sem implementar a lei geral após 30 meses de PROLOCAL: Bandeirantes, Bataguassu, Costa Rica, Mundo Novo e Selvíria.

Essa situação sugere estudo futuro para analisar se a condição fronteiriça interestadual poderia gerar desigualdades regionais mais 
profundas ou vulnerabilidade espacial para atingir níveis superiores de competitividade empresarial, uma vez que Costa Rica, Bataguassu, Selvíria e Mundo Novo, são limítrofes aos estados de: Goiás, São Paulo e Paraná, respectivamente. A guerra fiscal, o tratamento tributário diferenciado, medidas de desburocratização nesses estados avançaram mais ao comparar com Mato Grosso do Sul, como se atesta na recente instalação do Forum Permanente da MPE no MS, já consolidado para criação de ambiente favorável aos pequenos negócios nos estados vizinhos.

A evolução das formalizações está mais relacionada à economia de escala, condição econômica mais dinamizada em função de: numero de habitantes, investimentos privados mantidos pela Itaipu, pela fronteira comercial dinâmica com o Paraguai, por situar-se no eixo norte-sul de transporte da produção nacional, que requer prestação de serviços. Emerge ainda, a indústria de confecções, acompanhando o crescimento desse segmento na região sul do Estado.

Os números de formalizações nos municípios do PROLOCAL superam as expectativas para ambientes de baixo dinamismo econômico, a confiança de empreender está diretamente relacionada a criação de um ambiente favorável ao empreendedorismo e a produção, elementos diretos da inclusão produtiva. No aspecto de formalização, o PROLOCAL, indiscutivelmente gerou resultados positivos.

Ao analisar a condição do agente de desenvolvimento, relacionando aos vários papéis que direta ou indiretamente são desempenhados: seja articulação, adesão pública, a representação sócio-territorial local, o protagonismo, o enraizamento das competências, a capacidade de gestão, o protagonismo, enfim, a dependência do êxito do projeto com esse ator é plena. Neste ponto inclusive, reside importante reflexão comparativa ao programa DLIS, conforme Franco, 2002, o agente público mantém-se vulnerável a política partidária e mesmo havendo a formação dessa competência, ela será facilmente descartada de não houver uma blindagem quanto seu papel.

Mesmo com cuidados que excederam os preconizados na lei geral, pois no edital de seleção dos municípios para o PROLOCAL foi solicitada a nomeação de agentes com nível superior completo, enquanto a lei geral solicita apenas nível médio, esse risco permanece. Não há blindagem para que uma vez nomeado e recebendo seu plano de capacitações, esse agente poderá continuar a exercer suas funções de forma autônoma, independente das urnas.

As eleições municipais de 2012, refletiram nessa vertente o maior impacto para a geração de resultados do PROLOCAL. Dos 21 municípios alvo, 14 mudaram prefeitos, e mesmo com ações de sensibilização para continuidade dos agentes nomeados em 2011 e em plena execução do plano de ação do projeto, desses 14, apenas Nioaque manteve a agente nomeada pelo gestor anterior.

Dos municípios de fronteira aqui focados, houve derrota política da situação em Porto Murtinho e Mundo Novo. Apenas Aral Moreira elegeu-se para segundo mandato dando continuidade ao trabalho executado pela agente de desenvolvimento.

A descontinuidade da gestão pública em projeto de desenvolvimento local, mesmo com o cuidado de se formar uma rede de agentes com parceria privada, incluindo associações comerciais e sindicatos rurais, é fator deteriorador dos resultados. O retrabalho foi evidente. Além da desaceleração das ações em período de campanha política, o projeto PROLOCAL enfrentou a descontinuidade política de $2 / 3$ dos prefeitos dos territórios alvo dos projetos, desconstruindo o tecido institucional ora consolidado na ocasião.

No primeiro semestre de 2013, o monitoramento do PROLOCAL identificou que o projeto voltara praticamente para sua situação inicial novamente: gestores públicos novos, desconhecimento dos dispositivos da lei geral, municípios sem agentes de desenvolvimento nomeados, falta de capacitação, sem plano de ação para o desenvolvimento.

Tal constatação sugere um erro tático do PROLOCAL, o período de início. Este projeto pela sua complexidade deveria iniciar-se apenas no primeiro ano ou início do segundo ano de mandato do prefeito municipal, caso contrário, o investimento financeiro, técnico e a mobilização para resultados tornam-no desgastante, com baixa capacidade de produção de resultados num ciclo de projeto de três anos. Este também mostra-se, há seis meses para o término do projeto, um prazo insuficiente para transformações profundas e sustentáveis no município alvo. 
Ao buscar inclusão produtiva num cenário de crescimento econômico, orientase para uma visão compartilhada de futuro na qual a micro e a pequena empresa exerça papel de sustentação, que o caminho seja trilhado com planejamento participativo protagonizado por atores locais.

O PROLOCAL dialoga com os gestores públicos muitas vezes já cansados de buscar na atração de grandes indústrias, muitas vezes mal sucedidas em função da logística e da guerra fiscal, mostrando nos pequenos negócios a saída para a estagnação econômica dos municípios com a economia da proximidade, compras locais.

Também de forma assertiva o projeto ancora na identificação de oportunidades para os pequenos negócios, o estímulo ao empreendedorismo, a melhoria das capacidades locais, na inovação, para suprir vazios nas cadeias de fornecimento e assim gerar dinamismo local. Nessa lógica a prefeitu$\mathrm{ra}$, as escolas estaduais e quaisquer outros entes públicos locais, são percebidos como importante mercado consumidor local com amplitude para todos os setores produtivos, do agricultor familiar ao industrial.

Os ganhos obtidos pela ativação da economia local convertem-se em externalidades econômicas geradas pelas oportunidades que potencializam o território e empoderam seus habitantes de forma além do que seria inicialmente prevista.

Porém não basta trabalhar uma ponta do mercado, a demanda ou aqui especificamente o comprador público, mais ainda é necessário preparar a cadeia de fornecimento formada pelos pequenos negócios.

Os resultados econômicos do PROLOCAL, levantados por intermédio de entrevistas a empresários que investiram nas oportunidades apontadas no mapa de oportunidades dos 21 municípios diz respeito a inclusão produtiva dos agricultores familiares na cadeia de fornecimento.

A partir da priorização dos pequenos negócios nas compras públicas, as chamadas para compra de alimentação escolar com regras próprias do PNAE - programa nacional de alimentação escolar e do PAA - Programa de aquisição de alimentos, plenamente convergiram ao capitulo do uso do poder de compras da lei geral. OSEBRAE dispôs de equipes técnicas para orientar a produção compatível com as necessidades das escolas, e preparar o produtor para manter regularidade, qualidade, preço e gestão de fornecimento, essa ação deve continuar e ampliar escala.

A proposta do PROLOCAL, e consequentemente da implementação da lei geral, assegura que é possível dinamizar as economias dos pequenos municípios com os dispositivos do uso do poder de compras, no entanto, há que se investir de forma intensiva junto aos empresários que desconhecem que há benefícios garantidos por lei para sua participação em processos licitatórios.

Para efeito de consolidação e sustentabilidade dos resultados pretendidos pelo PROLOCAL, é necessário intensificar as ações no eixo do uso do poder de compras, pois é este que materializa em riquezas a evolução do processo. Acredita-se ainda que as compras públicas tem potencial para tornar-se ser o eixo indutor do processo de transformação dos pequenos municípios, impulsionando-os para adoção de melhorias em suas leis e procedimentos concernentes a desburocratização e a formalização de forma a torná-los compatíveis com o processo de desenvolvimento.

\section{Referências}

AMARAL FILHO, Jair do. É negócio ser pequeno, mas em grupo. In: SEMINÁRIO “DESENVOLVIMENTO EM DEBATE": EM COMEMORAÇÃO AOS 50 ANOS DO BNDES, 2002. Disponível em: <http://www.bndes. gov.br/SiteBNDES/export/sites/default/bndes_pt / Galerias/Arquivos>. Acesso em: 26 maio 2012.

BANDEIRA, Pedro S. Institucionalização de regiões no Brasil. Ciência e Cultura, ano 58, n. 1, p. 34-35, jan./mar. 2006. <http:// cienciaecultura.bvs.br/ scielo.php?pid=s0009-67252006000100015\&script=sci_ arttext>. Acesso em: 2 ago. 2013.

BOISIER, Sergio. Post-scriptum sobre Desarollo Regional: Modelos Reales y Modelos Mentales. EURE, Santiago, CL, v. 24, n. 72, p. 53-69, set. 1998.

DINIZ, Eli. “Governabilidade, Democracia e Reforma do Estado: Os Desafios da Construção de uma Nova Ordem no Brasil dos Anos 90". DADOS - Revista de Ciências Sociais, Rio de Janeiro, v. 38, n. 3, p. 385-415, 1995.

ESTERCI, Neide. O mito da democracia no país das bandeiras. Dissertação (Mestrado em Antropologia Social) - Museu Nacional, Universidade Federal do Rio de Janeiro, Rio de Janeiro, 1972.

KOTESKI, Marco Antonio. As micro e pequenas empresas no contexto econômico brasileiro. Revista FAE Business, n. 8, p. 16-18, maio 2004. Disponível em: <http:/ / www.fae.edu/publicacoes/pdf/revistadafae/faev8n1/ revfaev8n103koteski.pdf>. Acesso em: 2 ago. 2013. 
LE BOURLEGAT, Cleonice Alexandre. Desenvolvimento local na abordagem territorial do atual sistema-mundo. In: TREMBLAY, Gaetan; VIEIRA, Paulo Freire (Org.). O papel da universidade no desenvolvimento local. Florianópolis: APED, 2011. p. 107-122.

METZKER, Márcio. Tres anos da Lei Geral da Micro e Pequena Empresa. Brasília: Sebrae, 2009.

MODELOS mentales. EURE, Santiago, CL, v. 24, n. 72, p. 53-69, set. 1998.

NASSIF, Luís. Os cabeças-de-planilha. Rio de Janeiro: Ediouro, 2007.

NONAKA, Ikujiro; TAKEUCHI, Hirotaka. Criação de conhecimento na empresa: como as empresas japonesas geram a dinâmica da inovação. Rio de Janeiro: Campus, 1997. SERVIÇO DE APOIO AS MICRO E PEQUENAS EMPRESAS - SEBRAE. Plano de trabalho da rede de agentes de desenvolvimento. Abril, 2012.

Diretrizes estratégicas para implementação da lei geral nos municípios. Dez., 2011.

Sites:

Serviço Brasileiro de Apoio às Micro e Pequenas Empresas - SEBRAE - <www.sebrae.com.br>.

Serviço Brasileiro de Apoio às Micro e Pequenas Empresas do MS - SEBRAE/MS - <www.prolocal.ms.sebrae. com.br>. 